\title{
Assessment of the Results of Two Different Incision Techniques, Severity of the Symptoms and Functional Status in the Surgical Treatment of Carpal Tunnel Syndrome (CTS)
}

\author{
Levent Gürses*1 and Emine Arik ${ }^{2}$ \\ ${ }^{1}$ Health Sciences University, Dışkapı Ylldırım Beyazıt Training and Research Hospital Department of Neurosurgery Ankara, Turkey \\ ${ }^{2}$ Health Sciences University, Dışkapı Ylldırım Beyazıt Training and Research Hospital Department of Anesthesiology and Reanimation Ankara, Turkey
}

Received: April 20, 2018; Published: April 30, 2018

*Corresponding author: Levent Gürsesmd, Health Sciences University, Diskapi Ylldırım Beyazıt Training and Research Hospital Department of Neurosurgery Altındağ, Ankara, Turkey

Abstract

Aim: Evaluation of surgical outcomes of two different incisions in patients with CTS diagnosis

Materialsand Methods: The study included 100 patients who underwent surgical operation between January / 2017-January / 2018 at the Department of Neurosurgery in Health Sciences University, Dışkapı Yıldırım Beyazıt Training and Research Hospital. Median nerve decompression surgery was performed with standard longitudinal incision on 50 patients and with transverse mini incision on 50 patients. Patients were evaluated retrospectively according to the Boston Carpal Tunnel Syndrome Questionnaire (BCTQ).

Results: Patients who had surgery were divided into two groups according to the surgical technique applied and these groups were compared according to BCTQ in terms of symptom severity and functional status. In the postoperative period, the symptom severity scale in the Transverse Group was found to be less than in the Longitudinal Group and no complication involving the motor nerve was observed in any of the patients.

Conclusion: According to this study, the preference of the transverse mini-incision technique in hands experienced in the treatment of CTS surgery over the standard longitudinal technique reduces the severity of the symptoms felt by the patients during the postoperative period.

Keywords: Carpal Tunnel Syndrome; Boston Carpal Tunnel Syndrome Questionnaire; Transverse Mini Incision

Abbreviations: CTS: Carpal Tunnel Syndrome; BCTQ: Boston Carpal Tunnel Syndrome Questionnaire

\section{Introduction}

Carpal Tunnel Syndrome (CTS) is the most common pathology of peripheral nerve lesions seen in neurosurgery practice [1]. Today, the frequency of CTS increases in individuals who work with computers at desk along with other causes of medial neuropathy [2]. Physical examination findings and electrodiagnostic tests are important in the diagnosis of CTS [3]. In the treatment of CTS, median nerve decompression should be performed by surgical intervention in patients who do not respond to conservative methods (resting, medical treatment, physical therapy)[1,2]. Classical medical literature suggests longitudinal incision as the standard method [1-3]. Various techniques have been developed aiming at minimal skin incision concerning complications and healing problems $[4,5]$.

\section{Materials and Methods}

The study included 100 patients who were operated with standard longitudinal incision and transverse mini incision under local anesthesia between 1/January/2017 and 31/December/2017 at the Department of Neurosurgery in Health Sciences University, Dışkapı Yıldırım Beyazıt Training and Research Hospital. All patients were diagnosed with medical history, physical examination and EMG findings. Fifty patients who underwent median nerve decompression with standard longitudinal incision were named as Longitudinal Group; The other 50 patients who underwent median nerve decompression with transverse mini incision were named as Transverse Group. Both groups were compared preoperatively and 15 days after surgery according to the Boston Carpal Tunnel Syndrome Questionnaire (BCTQ) in terms of symptom severity and functional status.

\section{Results}

According to the Boston Carpal Tunnel Syndrome Questionnaire (BCTQ);Symptom severity scale in the transverse group was 40,2 preoperatively; 15,8 postoperatively, functional 
status scale was 27.3preoperatively; 16.5 postoperatively,Symptom severity scale in longitudinal group was; 41.5 preoperatively; 25.7 postoperatively;functional status scale was 28.1 preoperatively; 17.2 postoperatively.

There was no complication involving motor nerve in any patient.

\section{Discussion}

CTS is the most common pathology among the peripheral nerve lesions [1-3]. Nowadays, it is increasingly seen in persons who work with computers at desk [1-5]. CTS should be initially treated with medical and physical therapy modalities [1-3]. Surgical treatment should be performed in unresponsive patients[2,3,8]. The patients who are operated with a classical longitudinal incision (incision starting proximal to the superficial palmar arch, immediately followed by turning the wrist line at an angle of 45 degrees towards the ulnar side and passing the wrist line about $1 \mathrm{~cm}$ ) cannot use their hands for about 15 days due to postoperative pain, limitation of movement and scar tissue [6]. For these reasons, minimal approaches have been introduced in recent years in order to replace this surgical method [7]. The transverse mini-incision is a $2 \mathrm{~cm}$ section parallel to the wrist line in the pillar region. The severity of the symptoms is felt to be less due to the small size of the incision, lack of the scar tissue, and absence of limitation of movement.Less severity of symptoms such as day/night pain in the hand or wrist, loss of sensation and tingling is associated with the incision technique in the Transverse Group, compared with the longitudinal group. Although the standard longitudinal incision is a classical and safe approach, the minimally invasive operations performed in parallel to the wrist lines should be the preferred approach as it causes less severity in symptoms of day/night pain in the hand or wrist, loss of sensation, and tingling, as well as lack of scar tissue and shorter duration of healing.

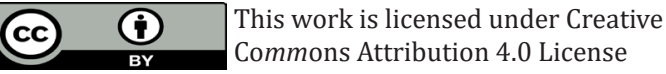

Submission Link: https://biomedres.us/submit-manuscript.php

\section{Conclusion}

According to this study, the preference of transverse mini-incision technique in hands experienced in CTS surgical treatment reduces the severity of symptoms in patients during the postoperative period compared to the standard longitudinal technique.

\section{References}

1. Kalliainen LK, Hermiz SJ (2018) Response: Evidence-Based Medicine: Current Evidence in the Diagnosis and Management of Carpal Tunnel Syndrome. Plast Reconstr surg.

2. Açıkgöz B, Sümer M Türk, Nöroşirürji Dergisi (2000) Carpal Tunnel Syndrome 10: 79-84.

3. Yıldız BT (2014) Carpal Tunnel Syndrome67(1): 1-4.

4. Jegal M, Woo SJ, Lee HI, Shim JW, Park MJ (2018) Anatomical Relationships Between Muscles Overlying Distal Transverse Carpal Ligament and Thenar Motor Branch of the Median Nerve. Clin Orthop Surg10(1): 89-93.

5. Branderi DJ, Mishra DG, Parikh SM, Sharma DB (2017) Computer use and Carpal tunnel syndrome. A Case- control Study21(3): 109-114.

6. Bai J, Kong L, Zhao H, Yu K, Zhang B, et al. (2014) Carpal Tunnel Release with a New Mini- Incision Approach Versus a Conventional Approach, a retrospective cohort study. Int J Surg 52: 105-109.

7. Ibrahim Burak Atcl, Serdal Albayrak,Türk Nöroşir Derg (2014)The Evaluation of Two Different Mini Incisions Distal and Proximal to the Pillar on functional outcomes in the Surgical Treatment of Carpal Tunnel Syndrome24(3): 275-279.

8. Huisstede BM, Randsdorp MS, Van Den Brink J Franke TP, Koes BW, Hoogvliet P (2018) The Effectiveness of Oral Pain Medication and Corticosteroid İnjections for Carpal Tunnel Syndrome-A Systematic Review.

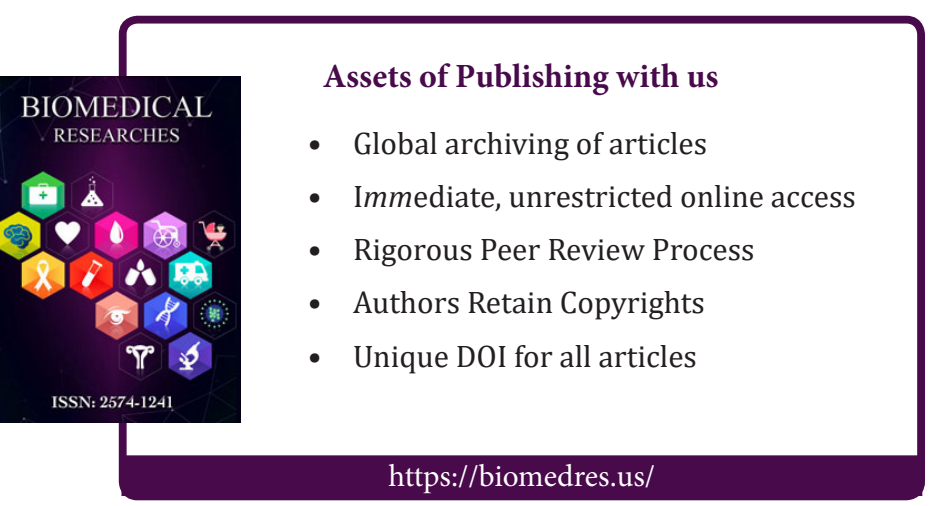

